\title{
Regimes de dosagem em patentes de segundo uso médico
}

\section{Dosing regimens in second medical use patents}

\author{
Regímenes de dosificación en patentes de \\ segundo uso médico
}

\section{Resumo}

No campo farmacêutico, o desenvolvimento de novos fármacos exige um grau sofisticado de entendimento de mecanismos fisiopatológicos, a fim de identificar e caracterizar potenciais alvos biomoleculares e prosseguir com os estudos clínicos. Dentro desse contexto, a proteção dos resultados de Pesquisa er Desenvolvimento é uma etapa vital para garantir o retorno financeiro dos pesados investimentos na área. Uma das estratégias para atingir tal objetivo consiste na exploração de patentes de segundo uso médico, usualmente redigidas no formato "uso do composto $X$ caracterizado pelo fato de ser empregado no preparo de medicamento para a doença $Y$ ”. Considerando o possível impacto social e a ausência de diretrizes específicas no Brasil, o presente artigo revisa os principais casos relacionados a regimes de dosagem na Europa e analisa os posicionamentos do Escritório Europeu de Patentes (EPO) e judiciários alemão e do Reino Unido sobre os requisitos de patenteabilidade e escopo de proteção, visando a contribuir com o debate técnico sobre o assunto.

Patentes; Uso de Medicamentos; Dosagem

\author{
Correspondência \\ C. A. Suganuma \\ Instituto de Pesquisas Tecnológicas de São Paulo. \\ Av. Prof. Almeida Prado 532, São Paulo, SP 05508-901, Brasil. \\ carlos.suganuma@usp.br \\ 1 Instituto de Pesquisas Tecnológicas de São Paulo, São Paulo, \\ Brasil. \\ 2 Universidade de São Paulo, São Paulo, Brasil.
}




\section{Introdução}

No campo farmacêutico, o desenvolvimento de novos fármacos exige um grau sofisticado de entendimento de mecanismos fisiopatológicos, a fim de identificar e caracterizar potenciais alvos biomoleculares e prosseguir com os estudos clínicos. A seleção dos mesmos e o conhecimento dos respectivos ciclos bioquímicos permitem a construção de bibliotecas de milhares de compostos com base em métodos de quantificação estrutura-atividade e modelagem molecular. Após, segue-se o screening, no qual serão avaliadas as propriedades de absorção, distribuição, metabolismo, excreção e dados toxicológicos, de modo a selecionar compostos líderes ou protótipos - etapa esta que demanda cerca de 3 a 5 anos. Aqueles com perfil de segurança satisfatório prosseguirão aos testes pré-clínicos (conduzidos in vitro e em animais). Na prática, estima-se que dentre cerca de 10 mil moléculas, somente 500 chegarão a ser testadas em animais, e em média apenas 10 restarão como candidatas aos centros de pesquisa clínica 1 .

Nesse contexto, o sistema de patentes é particularmente importante para a indústria farmacêutica; ao garantir o retorno financeiro sobre os investimentos, o Estado incentiva a inovação no setor e mitiga os riscos envolvidos no projeto. A análise desses documentos é um importante balizador na redução de duplicidade de pesquisa, além de constituir um parâmetro importante para a alocação de novos recursos em um dado projeto 2. Em 2013, estima-se que cerca de 2,6 milhões de pedidos de patentes foram depositados no mundo, representando um crescimento de $12 \%$ em relação a 20123. As patentes de segundo uso médico são consideradas particularmente relevantes para a gestão dos produtos da empresa, ao fornecer novas possibilidades terapêuticas e abreviar o screening por compostos protótipos 4 .

O conceito por trás de invenções de segundo uso está relacionado ao emprego de um composto X já conhecido, no preparo de medicamento para determinada moléstia Y (swiss claims ou reivindicações suíças) 5 . Um ponto controverso vem a ser a proteção de invenções de segundo uso médico envolvendo regimes de dosagem. Se um dado composto já é conhecido e pertencente ao estado da técnica, o "uso" deste em um novo regime de dosagem incorreria em um método terapêutico? Da mesma forma, a alteração da reivindicação de produto para uso poderia ser considerada adição de matéria?

No Brasil, a discussão sobre o tema é algo incipiente: o corpo normativo prevê a modalidade de proteção de uma segunda indicação médica e estabelece alguns critérios formais na elaboração das reivindicações, mas não especifica a abrangência de regimes de dosagem. Os excertos das Diretrizes de Exame de Patente de Invenção sobre o assunto são reproduzidos a seguir:

"Reivindicações de Uso

3.75 - Na área farmacêutica as reivindicações que envolvem o uso de produtos químico-farmacêuticos para o tratamento de uma nova doença utilizam um formato convencionalmente chamado de fórmula suiça: 'Uso de um composto de fórmula $X$, caracterizado por ser para preparar um medicamento para tratar a doença $Y$.'

3.76 - Ressalta-se que este tipo de reivindicação confere proteção para o uso, mas não confere proteção ao método terapêutico, o qual não é considerado invenção de acordo com o inciso VIII do art. 10 da LPI. Reivindicações do tipo 'Uso para tratamento', 'Processo/Método para tratamento', 'Administração para tratamento' ou seus equivalentes correspondem a reivindicações de método terapêutico e, portanto, não são consideradas invenção de acordo com o inciso VIII do artigo 10 da LPI" 6.

"Reivindicações de segundo uso

4.18 - Uma reivindicação para o uso não médico de um composto conhecido apresenta novidade, desde que este novo uso não tenha sido previamente colocado à disposição do público.

...Em reivindicações do tipo 'fórmula suiça' ('Uso de um composto de fórmula $X$, caracterizado por ser para preparar um medicamento para tratar a doença $Y^{\prime}$ ), a novidade é avaliada em função da doença a ser tratada..." 7 .

Considerando o possível impacto social da concessão de patentes de segunda indicação médica 8 , o presente artigo revisa os principais casos relacionados a regimes de dosagem na Europa e analisa o posicionamento deste ordenamento sobre os requisitos de patenteabilidade e escopo de proteção, visando a contribuir com o debate técnico sobre o assunto. 


\section{Metodologia}

A metodologia adotada consistiu em uma análise exploratória englobando processos relacionados ao tema em bases internacionais compreendidos entre 1970 e 2015, adotando como ponto de partida a semelhança entre as legislações nacional ${ }^{9}$ e europeia ${ }^{10}$, prosseguindo com a seleção de processos exemplificativos do ordenamento europeu. Apesar da jurisdição das cortes nacionais europeias serem independentes, é inegável a influência das Câmaras do Escritório Europeu de Patentes (European Patent Office - EPO), sendo consideradas altamente persuasivas pela especialização e tradição na área 11. Nesse sentido, analisaram-se os processos indexados na plataforma eletrônica Board of Appeal Decisions Database e na publicação Case Law of the Boards of Appeal 12 - esta última um compêndio das sentenças mais relevantes das Câmaras de Recursos do EPO - Boards of Appeal (BoA) e Enlarged Board of Appeal (EBA).

Em vista da maioria dos litígios envolvendo indústrias químicas e farmacêuticas entre 2000 e 2008 ocorrerem no Reino Unido 13, casos emblemáticos desta corte foram levantados com base na British and Irish Legal Information Institute.

Um ordenamento igualmente relevante é o alemão em virtude da experiência dos juízes na área, além de fornecer contrapontos importantes às interpretações do EPO e da Corte do Reino Unido. Uma dificuldade encontrada residiu na escassez de bases indexadoras de processos alemães em outros idiomas. Nesse sentido, optou-se por resgatar os mesmos baseando-se na análise de literatura especializada (artigos, livros e revisões) e citações em acórdãos de decisões correlatas. O teor das patentes em litígio e históricos administrativos foram recuperados na plataforma ESPACENET (https://world wide.espacenet.com/), mantida pelo EPO.

\section{Resultados e discussão}

No EPO, um dos primeiros processos relacionado ao segundo uso terapêutico foi T 92/82 referente ao composto brometo de butoxibenzilhiosciamina contra surdez e zumbido 13,14. O relatório descritivo indicava que a molécula já era conhecida por suas propriedades como agente antiulceroso e sofreu indeferimento pela Divisão de Exame por incidir em um método terapêutico, nos termos dos Artigos 52(4) e 54(1) da Convenção Europeia de Patentes (European Patent Convention - EPC) de 197310.

Em recurso, a requerente emendou a reivindicação principal para "uso do princípio ativo para o preparo de uma composição farmacêutica contra surdez e zumbido” 15, de forma a contornar a opinião desfavorável à patenteabilidade do pedido, ressaltando que os próprios Artigos 52 e 54 da EPC (1973) incorporavam a proteção de uso de um medicamento. Ao avaliar tal construção, a Câmara de Recursos lançara dúvidas acerca da admissão dessa alteração. Os excertos a seguir demonstram a controvérsia em relação ao assunto (tradução livre com grifos nossos) 10 :

“Artigo 52 - Invenções patenteáveis

(1) Patentes Europeias serão concedidas para quaisquer invenções que sejam suscetíveis de aplicação industrial, que sejam novas e que envolvam uma atividade inventiva.

(2) Os seguintes, em particular, não serão considerados como invenções na acepção do parágrafo 1:

(...)

(4) Métodos para tratamento do corpo humano ou animal por cirurgia ou terapia e métodos de diagnóstico praticados no corpo humano ou animal não serão considerados como invenções suscetíveis de aplicação industrial na acepção do parágrafo 1. Esta disposição não se aplica a produtos, em particular substâncias ou composições para uso em qualquer um destes métodos”.

O critério de novidade é expresso a seguir (tradução livre com grifos nossos) 10:

"Artigo 54 - Novidade

(1) Uma invenção deve ser considerada nova se não fizer parte do estado da técnica.

(2) O estado da técnica deverá ser considerado de modo a compreender tudo aquilo tornado acessível ao público por meio de uma descrição escrita ou oral, por uso, ou de qualquer outro modo, antes da data de depósito do pedido de patente europeu.

(...) 
(5) O disposto nos parágrafos 1 a 4 não exclui a patenteabilidade de qualquer substância ou composição, compreendida no estado da técnica, para uso em um método referido no artigo 52, parágrafo 4, desde que a sua utilização para qualquer método referido neste parágrafo não esteja compreendida no estado da técnica".

Em situação análoga, o processo T 128/82 16 relacionava um composto sem atribuir uma finalidade terapêutica específica. O quadro reivindicatório pleiteava esta e seus derivados na qualidade de substância farmacêutica ativa 17. O pedido de patente sofreu indeferimento pela Divisão de Exame por ausência de novidade (a família de compostos já pertencia ao estado da técnica, embora fossem desconhecidas as aplicações médicas até a data da prioridade). Em recurso, emendas ao quadro reivindicatório foram peticionadas, limitando a proteção da molécula ao uso terapêutico para combater insuficiência cerebral e aperfeiçoamento da habilidade intelectual em uma reivindicação de produto (composto) por "uso" em dada condição.

A Câmara de Recursos e a Divisão de Exame mantinham interpretações distintas acerca da palavra "a" ("um") do Artigo 54(5); não era claro se "a" discriminava um sentido numérico (um único método) 14,18. Em outras palavras, a proteção de compostos em uma segunda aplicação terapêutica não era prevista pelo arcabouço europeu.

\section{Decisões da Câmara Superior de Recursos: Eisai e Mobil}

\section{- G5/83/EISAI - reivindicações suíças}

Uma conclusão sobre o tema foi alcançada nas sete decisões G1-G7/83, todas de mesmo conteúdo, sendo a versão em língua inglesa G5/83/EISAI 19 a mais citada na literatura e jurisprudência. Nessa decisão, a Câmara Superior de Recursos europeia avaliou dois formatos de reivindicação provenientes das jurisdições alemã e suíça. A fórmula adotada pela Suprema Corte Federal alemã em X ZB 4/83 Hydropyridin 16 associou o conceito de augenfällige Herrichtung - "preparo para administração" (do medicamento), em uma tradução aproximada - ao formato "uso de um medicamento $X$ para tratamento de uma doença Y"; ou seja, seu escopo afastaria os atos de embalagem, instruções e outras medidas que induzam ao tratamento de Y por meio de X. Esse formato seria privilegiável, excetuando-se os métodos de tratamento do corpo humano por terapia que ocorram completamente fora do setor industrial 4,20. Em contraste, a redação proposta pelo Escritório de Propriedade Intelectual suíço consistia em "uso de X para preparo de medicamento para tratamento de doença $Y$ ”. Argumentou-se não haver aqui a proteção de um método terapêutico, mas sim a um processo de preparo de um medicamento contendo X para combater Y.

A Câmara Superior de Recursos concluiu que as reivindicações de "método compreendendo etapas" e "uso de algo para determinado propósito" (a sequência de etapas implicada) seriam mera questão de preferência linguística, não havendo qualquer distinção entre si. Assim, a formulação de "uso de componente $X$ para tratamento de enfermidade Y” recairia nas proibições legais da EPC ao contrário do que propunha a jurisprudência alemã. Por outro lado, a Câmara aduziu não haver incompatibilidade quanto à nova e inventiva utilização de uma substância ou composição na fabricação de medicamento para tratamento terapêutico, proposta pelo escritório suíço 14,19 .

Embora divergentes, o escopo das reivindicações suíça e alemã foi posteriormente equiparado na Alemanha 21. Todavia, a decisão G5/83/EISAI não sistematizou formas de aferir os elementos técnicos essenciais - aqueles que contribuem para a solução do problema técnico objetivo - em uma reivindicação de uso. Uma das dificuldades na prática era a harmonização entre o uso de um elemento pertencente ao estado da técnica e o requisito de novidade.

\section{- G2/88/MOBIL - novidade e efeito técnico}

A decisão G2/88/MOBIL 22 forneceu maiores esclarecimentos sobre o assunto. A reivindicação principal da patente em discussão se referia a uma composição lubrificante compreendendo: uma maior parte de um óleo lubrificante; ao menos um por cento em peso do aditivo 23; esta formulação permitia reduzir o atrito entre superfícies deslizantes em motores. Nos procedimentos de oposição alegou-se falta de novidade e atividade inventiva frente a anterioridades que descreviam o aditivo e seu uso para 
inibição de ferrugem. A depositante, em requerimento auxiliar, emendou a reivindicação principal para "uso de pelo menos $1 \%$ em peso com base na composição total como aditivo redutor de atrito em uma composição lubrificante que compreende uma porção principal de um óleo lubrificante" 24. Essa redação remetia ao formato suíço (uso dos compostos para preparo de aditivos em uma composição lubrificante), o que justificou uma consulta à Câmara Superior de Recursos a se posicionar sobre a novidade pelo propósito, adição de matéria e a possibilidade da alteração da categoria de reivindicação de produto para uso durante os procedimentos de oposição 14,22 .

A Câmara Superior notou que as provisões contra adição de matéria não obrigatoriamente impedem a alteração de categoria de reivindicação de "produto" para "uso", devendo ser avaliada caso a caso como qualquer outra emenda. Sobre a novidade pelo propósito, enfatizou-se a importância do efeito técnico proporcionado pelo conjunto de elementos técnicos essenciais. Para a Câmara Superior de Recursos, o elemento técnico essencial em patentes de segundo uso está no contexto da obtenção do mesmo, afastando-se da "doutrina da inerência", em que o emprego de um composto conhecido para finalidade diversa do estado da técnica seria automaticamente desprovido de novidade.

Como exemplo, a Câmara citou o caso T 231/85; nesta decisão, a patente sob recurso descrevia um conjunto de princípios ativos conhecidos por sua influência positiva no crescimento de plantas e reivindicava o uso destes para controle de populações de fungos. Apesar de seu comportamento como promotor de crescimento de espécies vegetais resultar na ação microbicida, a invenção revelava pela primeira vez uma forma intencional de se controlar a proliferação fúngica. Dessa distinção decorre que o fato do composto ser conhecido não exclui a novidade de um uso desconhecido dessa substância "mesmo que o novo uso não requeira qualquer realização técnica além do uso até então conhecido da mesma substância" 25. Com efeito, prevaleceu em G2/88/MOBIL que a ausência de novidade pressupõe a antecipação de todos os dados ou informações para a execução ou funcionamento de maneira inequívoca da aplicação, sendo o elemento técnico de natureza funcional. Embora essa decisão não se refira a invenções farmacêuticas, suas conclusões se estenderam a estas últimas por força de mérito 12 .

A partir de G5/83/EISAI e G2/88/MOBIL, depreende-se que a mera sugestão de ocorrer o efeito técnico não constitui um argumento definitivo para afastar a novidade da matéria. A decisão T 0385/07 26 se relacionava ao uso de aplidina para a fabricação de um medicamento contra câncer pancreático, de modo a prevenir o risco de desenvolvimento de tumores e metástases. Uma anterioridade detalhava dois ensaios clínicos: no primeiro, dentre 30 pacientes somente um tinha câncer pancreático e no segundo, dos 43 , apenas quatro eram portadores desta doença. Em ambos os ensaios não se especificou a dosagem aplicada ao grupo portador de câncer pancreático; como as condições relatadas no pedido de patente não haviam sido reveladas pelos estudos clínicos, a Câmara ponderou que a capacidade antitumoral de um medicamento em um determinado câncer não pode ser utilizada como modelo em outros tipos por conta da diversidade das etiologias, alterações fisiopatológicas e metástases - o que afastou as alegações de ausência de novidade e atividade inventiva sobre a matéria.

Em termos de suficiência descritiva consolidou-se a não obrigatoriedade da apresentação de testes clínicos em humanos; diversos casos demonstraram que este critério pode ser amparado por evidências in vitro (modelos laboratoriais) ou em estudos com animais associados à aplicação em tela, conforme exposto em T 1642/06 27. A apresentação desses dados pode ser posterior à publicação do pedido, desde que no intuito de suportar as informações previamente contidas na especificação da patente. Em T 0609/02 28, postula-se que se o teor do relatório provê apenas evidências vagas sobre um possível uso médico, testes posteriores não conseguirão remediar a ausência de suficiência descritiva.

\section{Regimes de dosagem}

Regimes de dosagem consistem em uma sistematização do tratamento de um paciente, abarcando a administração do fármaco, número de doses em dado período de tempo e intervalo necessário entre as mesmas. O desenvolvimento de novos regimes no ambiente clínico permite a redução de eventos adversos, otimização da farmacocinética e biodisponibilidade e aumento na adesão do paciente ao tratamento 29 .

A decisão T1020/03 avaliou o patenteabilidade do uso de fatores de crescimento de insulina do tipo I (insulin-like growth factor-I - IGF-I) para o preparo de medicamento a ser administrado em um 
mamífero, de maneira descontínua. Trata-se de uma proteína sintetizada no fígado em resposta ao hormônio de crescimento $(\mathrm{GH})$. A Divisão de Exame alegou que ao determinar a melhor forma de prescrição de regimes de fármacos para as necessidades do paciente tem-se as atividades típicas de médicos, cuja proteção patentária é vedada. Ensaios anteriores testaram a eficácia desse polipeptídeo sob doses de 120 a $160 \mu \mathrm{g} / \mathrm{kg}$ para diabetes do tipo II, mas a alta incidência de efeitos adversos superava as melhorias na função renal do paciente (aumento da taxa de filtração glomerular). A administração intermitente como revelada nos estudos clínicos da patente permitia a obtenção de um efeito terapêutico menos deletério, com menor incidência de reações adversas. A Câmara de Recursos discordou da Divisão de Exame em estudo detalhado, pontuando o fato de a reivindicação principal direcionar ao uso do composto para o preparo de medicamento não interferir no trabalho do profissional da saúde. Destacou também que nenhuma das anterioridades apontadas indicava ou detalhava um tratamento de IGF-I intermitente com pronunciada redução dos efeitos adversos. A Câmara aderiu ao princípio de que um novo e inventivo regime seria absolutamente válido ao expandir o leque de possibilidades terapêuticas a segmentos mais vulneráveis da mesma forma que uma nova via de administração ou grupo de pacientes 30 .

O caso T 1319/04 31 foi igualmente emblemático. O pedido de patente em tela pleiteava o uso de ácido nicotínico ou seu metabólito para comprimidos de liberação prolongada em hiperlipidemias uma vez ao dia, antes do repouso. Diversos documentos identificados pela Divisão de Exame de Patentes previam a administração do composto para hiperlipidemias em formas farmacêuticas de liberação prolongada. Esse pedido (indeferido por ausência de novidade e incidência em método terapêutico) seguiu então à Câmara de Recursos. A requerente admitiu que o elemento técnico residia no regime de ácido nicotínico uma vez ao dia antes do repouso e salientou que nenhum documento do estado da técnica indicava ou sugeria esta abordagem. Diante dessa situação, direcionou-se uma consulta à Câmara Superior de Recursos em relação à patenteabilidade de novos regimes de dosagem sob a égide das novas provisões legais da EPC (2000). A reforma da EPC eliminara as ambiguidades constatadas nos Artigos 52 e 54 da EPC (1973), removendo qualquer dúvida sobre a patenteabilidade de substância ou composição e novos usos das mesmas, além de instituir a proteção de um "produto por sua função" 32. Não estava esclarecido, no entanto, a questão da permanência da fórmula suíça e se novos regimes de dosagem seriam patenteáveis.

$\mathrm{O}$ alinhamento entre a EPC e as reivindicações de uso de um princípio ativo caracterizado por novo regime de dosagem foi atingido em G2/08/ABBOTT 33. A Câmara Superior de Recursos ao se debruçar sobre as dúvidas suscitadas em T 1319/04 determinou que a fórmula suíça instituída em Eisai não mais seria aceita face ao novo Artigo 54(5) - cessante ratione legis, cessat et ipsa lex - e decretou um prazo de três meses para a adequação dos futuros pedidos. Em adição, não descartou a hipótese de regimes de dosagem novos e não óbvios serem patenteáveis, frisando, contudo, a necessidade do efeito técnico comprovado e não somente uma mera alegação no texto de patente.

Nas cortes nacionais europeias um debate notável sobre o assunto ocorreu em Bristol Myers Squibb (BMS) vs. Baker Norton Pharmaceuticals 34, formulado pela England and Wales Court of Appeal. Nos quadros de câncer de ovário, recomendava-se como terapia de primeira linha a infusão de paclitaxel durante $24 \mathrm{~h}$ em doses acima de $170 \mathrm{mg} / \mathrm{m}^{2}$. Esse princípio ativo apresentava restrições farmacotécnicas devido à sua baixa solubilidade em água; a combinação com emulsificantes nos ensaios clínicos de fase I havia provocado reações alérgicas em parte da população amostral, além de imunossupressão. A patente EP 0584001 reivindicava o uso do paclitaxel para a mesma patologia em dosagens de $135 \mathrm{mg} / \mathrm{m}^{2}$ a $175 \mathrm{mg} / \mathrm{m}^{2}$ durante três horas ou menos, alegando haver redução sensível da neutropenia. Em procedimento de nulidade argumentou-se que a EP 0584001 não era nova e incidia em um método terapêutico. Buxton LJ ao ponderar sobre os limites da decisão Eisai, avaliou que uma patente de segundo uso deveria apresentar uma finalidade médica distinta da primeira; se a novidade reside na natureza do uso (por exemplo, na dosagem), trata-se de método terapêutico e, portanto, não privilegiável. A redução de neutropenia foi considerada como um "bônus" obtido pela mera aplicação dos ensinamentos no estado da técnica, em uma dosagem específica.

O tribunal alemão manteve algumas reservas a esse entendimento em Carvedilol II 35. O quadro reivindicatório da patente em tela (EP0808162, Boehringer) é reproduzido a seguir:

"1. The use of compound which is both a beta-adrenoreceptor antagonist and a alfa-adrenoreceptor antagonists for the manufacture of a medicament for decreasing mortality resulting from congestive heart failure in 
mammals, alone or in conjunction with one or more other therapeutic agents, said agents selected from the group consisting of an angiotensin converting enzyme inhibitor, a diuretic and a cardiac glycosides.

(...)

3. The use of a compound according to claim I or 2, wherein said compound is Carvedilol.

4. The use of a compound according to claim 3. wherebv a pharmaceutical formulation containing either 3.125 or $6.25 \mathrm{mg}$ carvedilol in a single unit are administered for a period of 7-28 days, once or twice daily as an initial dose" 35 .

A Suprema Corte Alemã (Bundesgerichtshof) interpretou essa redação como um método terapêutico, salientando que qualquer especificação na dosagem deve ser restrita à etapa de preparo na fabricação e não em relação à sua administração. Nota-se que nesse formato o elemento técnico essencial (dosagem) é associado ao preparo do medicamento, ao invés do tratamento médico propriamente dito 36.

As decisões mencionadas não encerraram o tema: um reexame de BMS vs. Baker Norton na Corte do Reino Unido ocorreu em Actavis UK vs. Merck and Co. 37. No estado da técnica, o composto finasteride era prescrito para o tratamento de hiperplasia prostática benigna - patologia associada à presença de dihidrotestosterona (DHT), um metabólito da testosterona. Sabia-se que finasteride inibia a isoenzima de conversão 5-alfa-redutase tipo II, reduzindo a síntese de DHT. Da mesma forma, era conhecido que quadros de alopecia androgênica estavam relacionados à presença deste composto no couro cabeludo, além de existir evidências de que o finasteride poderia ser um tratamento para esta desordem em doses compreendidas entre 5 a $2.000 \mathrm{mg}$.

A patente sob litígio (EP0724444, Merck) pleiteava o uso de finasteride para o tratamento de alopecia androgênica em doses de 0,05 a 1,00mg. No processo de nulidade judicial, Actavis questionou sua atividade inventiva e alegou tratar-se de um método terapêutico face às conclusões de EISAI em conjunto com BMS vs. Norton Baker Co. (mera variação no regime de dosagem para uma patologia). A Corte Britânica avaliou que a decisão em BMS não poderia ser extrapolada a todos os casos e refutou tal afirmação em vista dos argumentos apresentados por Merck. Essa última concordou com todos os pontos, afirmando que o técnico no assunto poderia ser motivado a reduzir as dosagens e antecipar o teor revelado na patente. No entanto, destacou que o mesmo também estaria ciente de estudos anteriores à data de prioridade, que concluíam haver um predomínio da enzima 5-alfa-redutase tipo I no escalpo, não sendo detectada a isoenzima tipo II nesta região. A distribuição das isoenzimas tipos I e II no corpo humano era desconhecida na época, e com base nesses documentos o técnico não seria motivado a prosseguir com novos experimentos para o tratamento de alopecia, uma vez que o alvo do composto era a isoenzima tipo II. Nesse sentido, a patente foi declarada inventiva em relação à arte anterior.

Dentre a família de patentes dos processos europeus citados, apenas EP0808162 (Carvedilol II) e EP0643965 (relacionada aos processos T 1319/04 e G2/08/ABBOTT) tiveram extensões ao Brasil com avaliação de mérito. A família da patente EP0808162 compreende os pedidos PI9607111-7 acerca de formulações de Carvedilol e sua divisão PI9612953-0, relacionada ao uso de tais formulações para insuficiência cardíaca congestiva. Ambos os pedidos foram objeto de parecer técnico negativo pelo Instituto Nacional de Propriedade Industrial - INPI (ausência de atividade inventiva), sem contestação por parte do depositante.

Por sua vez, a patente EP0643965 detém em sua família dois pedidos nacionais: PI9815457-5 (kit contendo formulações de ácido nicotínico) e PI9815454-0, no qual reivindica uma composição caracterizada pelo regime de dosagem, nos moldes de EP0643965. Nesse caso, o exame do INPI apontou diversas anterioridades relevantes que combinadas previam tal proposta. Emendas efetuadas pela titular para composições caracterizadas por apresentar hepatotoxicidade limitada não foram suficientes para provar sua atividade inventiva, sendo esse pedido posteriormente indeferido em grau de recurso.

\section{Escopo de proteção e hipóteses de infringência}

O escopo de proteção de uma patente concedida e vigente é determinado pelo quadro reivindicatório, suportado pelo teor de seu relatório descritivo. Nesse sentido, o estabelecimento de infringência ocorre mediante a apresentação de evidências que comprovem a violação a uma ou mais reivindicações independentes 38 . 
$\mathrm{Na}$ avaliação de infringência direta de patentes envolvendo regimes de dosagem, os tribunais do Reino Unido e da Alemanha empregam os mesmos critérios aplicados às patentes de segundo uso médico tradicionais. Na decisão Actavis vs. Merck mencionada anteriormente, Jacob J. enfatizara a importância da bula do medicamento: há infringência se as indicações terapêuticas apontarem para o uso patenteado. Alguns autores são céticos quanto a esse requisito per se e recomendam averiguar uma pluralidade de evidências como a intenção da empresa de genéricos (documentos internos relativos ao tamanho e natureza da oportunidade comercial), market share das diferentes indicações (se o mercado para a indicação de origem é trivial em relação ao mercado do uso patenteado, o grande volume de vendas do genérico seria um indicativo forte de que o medicamento está conscientemente sendo vendido para o uso protegido), práticas de prescrição dos médicos (possibilidade de prescrição off-la$b e l$ ), as medidas adotadas visando à promoção do uso ilícito (ou as medidas tomadas para minimizar o mesmo) e se a bula destaca as indicações carve-out (por exemplo, "X contido no produto $Y$ também pode ser/é também utilizado para tratar outras condições não mencionados nesta bula”) 39.

Por outro lado, os tribunais alemães adotam o princípio de sinnfällige Herrichtung ou "preparo evidente" 38. Trata-se de um conjunto de indícios utilizados para aferir a existência de contrafação, amparado por uma série de decisões relacionadas ao tema (incluindo o processo Hydropyridin mencionado anteriormente). Esse conceito relaciona a infringência de patentes de segundo uso a todas as etapas prévias envolvidas no preparo do medicamento, incluindo rotulagem, embalagem e instruções escritas. Em Comitê da Association Internationale Pour La Protection de la Propriété Intellectuelle (AIPPI) sobre o assunto, o grupo alemão ressalvou a importância da embalagem e da bula no ajuizamento de uma ação de contrafação por serem as únicas evidências concretas para a comprovação do delito 5,38. Uma peculiaridade no ordenamento alemão é o fato de poder haver infringência por um médico uma vez que não se trata de um uso privado; todavia, alguns autores sustentam que nesta situação não ocorre infração, uma vez que inexiste uma relação entre o material especificando a dosagem e a produção do medicamento tal como estabelecido pelo princípio de "preparo evidente" 40.

\section{Considerações finais}

O desenvolvimento de novas abordagens no ambiente clínico torna necessário o esclarecimento das condições de aplicação e exemplos de formulações no preparo do relatório de patente. De modo geral, a postura da Câmara Europeia e das Cortes estudadas consiste em equilibrar os direitos de privilégio e não prejudicar o desenvolvimento de possibilidades terapêuticas. O "uso" está relacionado ao preparo do medicamento e não a um tratamento ou diagnóstico, assim como a inexistência de novidade exige evidências que prevejam de maneira inequívoca a dosagem pleiteada sem demandar ensaios e/ou experimentos exaustivos. Não se observa também o aumento do escopo; a proteção de um regime não afasta a fabricação e comercialização da composição propriamente dita. Por outro lado, é necessário comprovar as alegações apontadas na patente com ensaios clínicos ou in vitro.

Dentro desse contexto, em infrações de patentes de segundo uso médico protegendo regimes de dosagem, os tribunais europeus exigem o estabelecimento de uma relação íntima entre o material que especifica a dose e o produto comercializado. Essa é uma situação ainda não discutida pela doutrina ou jurisprudência nacional, tornando a análise dos processos citados importante para a construção do equilíbrio de direitos. 


\section{Referências}

1. Patrick GL. An introduction to medicinal chemistry. 5th Ed. Oxford: Oxford University Press; 2013.

2. Bergström JL. Pharmaceutical patent strategies - the competition between originator and generic companies within the European Union [Dissertação de Mestrado]. Jönköping: Jönköping International Business School, Jönköping University; 2010.

3. World Intellectual Property Organization. WIPO IP facts and figures. WIPO Publication No. 943E/14. http://www.wipo.int/portal/en/ index.html (acessado em 24/Jun/2015).

4. Lönnqvist P. Andra medicinska indikationen [Dissertação de Mestrado]. Helsinki: Faculty of Law, University of Helsinki; 2009.

5. Association Internationale pour la Protection de la Propriété Intellecuelle. Second medical use and other second indication claims. Working Guidelines, AIPPI Q238. https:// www.aippi.org/download/commitees/238/ WG238English.pdf (acessado em 06/ Out/2015).

6. Instituto Nacional da Propriedade Industrial. Resolução da Presidência no 124/2013. Institui as diretrizes de exame de pedidos de patente Bloco I - Conteúdo do Pedido de Patente. Revista da Propriedade Industrial 2013; (2241). http://revistas.inpi.gov.br/rpi.

7. Instituto Nacional da Propriedade Industrial. Resolução da Presidência no 169/2016. Institui as diretrizes de exame de pedidos de patente Bloco II. Revista da Propriedade Industrial 2016; (2377). http://revistas.inpi.gov.br/rpi.

8. Oliveira RB. A patenteabilidade do segundo e posteriores usos médicos no Brasil [Tese de Doutorado]. Rio de Janeiro: Programa de Pósgraduação em Políticas Públicas, Estratégias e Desenvolvimento, Instituto de Economia, Universidade Federal do Rio de Janeiro; 2012.

9. Brasil. Lei no 9.279, de 14 de maio de 1996. Regula direitos e obrigações relativos à propriedade industrial. Diário Oficial da União 1996; 15 mai.

10. European Patent Office. European Patent Convention (1973). http://www.epo.org/lawpractice/legal-texts/html/epc/1973/e/con tents.html (acessado em 05/Mar/2015).

11. United Kingdom House of Lords. Merrell Dow Pharmaceuticals Inc v HN Norton \& Co Ltd. http://www.bailii.org/uk/ cases/UKHL/1995/14.htm (acessado em 10/ Ago/2015).

12. European Patent Office. Case law of the Boards of Appeal - September 2013. http:// documents.epo.org/projects/babylon/ eponet.nsf/0/4CCF968D57494023C125 7C1C004F992C/\$File/case_law_of_the_ boards_of_appeal_2013_en.pdf (acessado em 05/Mar/2015).

13. Cremers K, Ernicke M, Gaessler F, Harhoff D, Helmers C, McDonagh L, et al. Patent litigation in Europe. http://ftp.zew.de/pub/ zew-docs/dp/dp13072.pdf (acessado em 02/ Fev/2015)
14. Suganuma C. A perspective on second medical indication patents in Brazil. Pharmaceutical Patent Analyst 2016; 5:91-5.

15. Eisai Co. Ltd. Yuasa Ryo. Use of butoxybenzylhyoscyamine bromide in pharmaceutical compositions against deafness and tinnitus. IPC: A61K31/46. EP0002051 (A1), 1977-1116, 1979-05-30. http://worldwide.espacenet. $\mathrm{com} /$ (acessado em 05/Mai/2015).

16. European Board of Appeal. T 0128/82 (Pyrrolidin-Derivates) Hoffmann-La Roche. 12.1.1984. http://www.epo.org/law-practice/ case-law-appeals/recent/t820128ep 1.html (acessado em 15/Jul/2015).

17. Hoffmann-La ROCHE. Kyburz Emilio, Aschwanden Werner. Pyrrolidine derivatives for use as therapeutically active substances and medicaments containing them. IPC: A61K31/40. EP 0003602 (A1), 1978-02-10, 1979-08-22. http://worldwide.espacenet. $\mathrm{com} /$ (acessado em 06/Mai/2014).

18. Ventose E. Patent protection for second and further medical uses under the European Patent Convention. Scripted 2009; 6:57-74.

19. European Enlarged Board of Appeal. G5/83/ EISAI. Second medical indication. 05.12.1984. http://www.epo.org/law-practice/case-lawappeals/recent/g830005ep1.html (acessado em 18/Jul/2014).

20. Bundesgerichtshof. Beschl. v. 20.09.1983, Az.: X ZB 4/83. "Hydropyridin". https://www.juri on.de/Urteile/BGH/1983-09-20/X-ZB-4_83 (acessado em 06/Jul/2014).

21. DC Düsseldorf. 4 O $187 / 99$ "NMR-Contrast Agents". 08.09.1999. http://www.darts-ip.com (acessado em 15/Jul/2015).

22. European Enlarged Board of Appeal. G2/88/MOBIL. Friction reducing additive. 11.12.1989. http://www.epo.org/law-prac tice/case-law-appeals/recent/g880002 ex 1 . html (acessado em 18/Jul/2014).

23. Mobil Oil Corp. Horodysky Andrew G, Andress Harry John Jr. Friction reducing additives. IPC: C07F5/04. EP 0036708 (A1), 1980-03-24, 1981-09-30. http://worldwide. espacenet.com (acessado em 06/Mai/2014).

24. European Board of Appeal. T 0059/87/Friction reducing additive / MOBIL II. 26.4.1988. http://www.epo.org/law-practice/case-lawappeals/recent/t870059ex2.html (acessado em 15/Jul/2015).

25. European Board of Appeal. T 0231/85 (Triazole derivates)/BASF. 8.12.1986. http:// www.epo.org/law-practice/case-law-appeals/ recent/t850231 ep1.html (acessado em 15/ $\mathrm{Jul} / 2015)$.

26. European Board of Appeal. T 0385/07 (Aplidine) Pharma Mar. 5.10.2007. http://www.epo. org/law-practice/case-law-appeals/advancedsearch.html (acessado em 18/Jul/2015).

27. European Board of Appeal. T 1642/06 (Sigma receptor) Spruce, Barbara, et al. 23.8.2007. http://www.epo.org/law-practice/case-lawappeals/recent/t061642eu1.html (acessado em 18/Jul/2015). 
28. European Board of Appeal. T 0609/02 (AP1 complex) The Salk Institute for Biological Studies v. Karo Bio AB / Astra AB. 27.10.2004. http://www.epo.org/law-practice/case-lawappeals/recent/t020609eu1.html (acessado em 16/Jul/2014).

29. Hsiao J, Wang W. Dosage patenting in personalized medicine. http://bciptf.org/wp-con tent/uploads/2012/06/Dosage_Patenting_in_ Personalized_Medicine.pdf (acessado em 06/ Mai/2015).

30. European Board of Appeal. T 1020/03 (Method of administration of IGF-I) Genentech Inc. 29.10.2004. http://www.epo.org/lawpractice/case-law-appeals/recent/t031020 ex1. html (acessado em 16/Jul/2015).

31. European Board of Appeal. T 1319/04 (Dosage regimen) Kos Life Sciences, Inc. 22.4.2008. http://www.epo.org/law-practice/case-lawappeals/recent/t041319ex1.html (acessado em 18/Jul/2014).

32. European Patent Office. European Patent Convention (2000). http://www.epo.org/lawpractice/legal-texts/epc.html (acessado em 05/ Mar2015).

33. European Enlarged Board of Appeal. G2/08/ ABBOTT RESPIRATORY Dosage regime. 19.2.2010. http://www.epo.org/law-practice/ case-law-appeals/recent/g080002 ex 1.html (acessado em 18/Jul/2015).
34. England and Wales Court of Appeal. Bristol Myers Squibb Co v. Baker Norton Pharmaceuticals Inc. http://www.bailii.org/ew/cases/ EWCA/Civ/2000/169.html (acessado em 10/ Ago/2015).

35. Bundesgerichtshof. X ZR 236/01 - "Carvedilol II”. 17.01.2006. http://lexetius.com/2006,3749 (acessado em 06/Jul/2015).

36. Rudge A. Guide to European Patent Law, 2013 edition. Eagan: Thomson West; 2013. (Intellectual Property International International Series).

37. England and Wales Court of Appeal. Actavis UK Ltd v. Merck \& Co Inc. http://www.bailii. org/form/search_multidatabase.html (acessado em 10/Ago/2015).

38. Grubb PW, Thomsen PR. Patents for chemicals, pharmaceuticals, and biotechnology: fundamentals of global law, practice and strategy. 5th Ed. Oxford: Oxford University Press; 2010.

39. Parker S, Hall B. Skinny labeling infringement: finding a fair remedy. Intellectual Property Magazine 2013; 3 set. http://www.intellec tualpropertymagazine.com/patent/skinnylabelling-infringement-finding-a-fair-reme dy-91356.htm.

40. Kanz C, Gerhardt F. What are the risks of second medical use and dosing regimens in pharmaceutical patenting? Pharmaceutical Patent Analyst 2014; 3:481-4. 


\section{Abstract}

In the pharmaceutical field, the development of new drugs requires sophisticated understanding of pathophysiological mechanisms in order to identify and characterize potential biomolecular targets and proceed with clinical trials. In this context, protection of research and development results is a vital stage for guaranteeing financial return on the heavy investments in the area. One strategy to achieve this objective is to exploit second-use patents, usually drafted in the format "use of compound $X$ characterized by the fact that it is used in preparing a drug for disease Y". Considering the possible social impact and lack of specific guidelines in Brazil, this article reviews the principal cases related to dosing regimens in Europe and analyzes the positions of the European Patent Office (EPO) and German and UK judiciary systems on the requirements for patentability and scope of protection, aimed at contributing to the technical debate on the topic.

Patents; Drug Utilization; Dosage

\section{Resumen}

En el campo farmacéutico, el desarrollo de nuevos fármacos exige un grado de sofisticación en la comprensión de los mecanismos fisiopatológicos, con el fin de identificar y caracterizar potenciales objetivos biomoleculares y proseguir con los estudios clínicos. Dentro de este contexto, la protección de los resultados de Investigación y Desarrollo es una etapa vital para garantizar el retorno financiero de las costosas inversiones en este área. Una de las estrategias para alcanzar tal objetivo consiste en la explotación de patentes de segundo uso médico, habitualmente redactadas en el formato "uso del compuesto X, caracterizado por el hecho de ser empleado en la preparación del medicamento para la enfermedad $Y^{\prime \prime}$. Considerando el posible impacto social, y la ausencia de directrices especificas en Brasil, el presente artículo revisa los principales casos relacionados con los regimenes de dosificación en Europa y analiza las posiciones adoptadas por la Oficina Europea de Patentes $(E P O)$ y los sistemas judiciales alemanes y del Reino Unido sobre los requisitos de patentabilidad $y$ alcance de la protección, con el objetivo de contribuir al debate técnico sobre este asunto.

Patentes; Utilización de Medicamentos;

Dosificación
Recebido em 03/Jun/2016

Versão final reapresentada em 01/Nov/2016

Aprovado em 28/Nov/2016 